\title{
Fracture Life Estimation of Al-1050 Thin Beams using Empirical data and Numerical Approach
}

M. Ali Khan ${ }^{* * 1}$, Kamran A. Khan'², Sohaib Z. Khan ${ }^{3}$, Salman Nisar ${ }^{4}$, Andrew Starr ${ }^{1}$

${ }^{1}$ Dept. of Aerospace, Transport and Manufacturing, Cranfield University, Cranfield, United Kingdom

${ }^{2}$ Dept. of Aerospace Engineering, Khalifa University of Science, Technology and Research (KUSTAR), Abu Dhabi, UAE

${ }^{3}$ Dept. of Mechanical Engineering, Islamic University of Madinah, Madinah, Saudi Arabia

${ }^{4}$ Dept. of Industrial and Manufacturing, National University of Sciences and Technology, Karachi, Pakistan

** Corresponding author: muhammad.a.khan@cranfield.ac.uk

\begin{abstract}
A technique based on empirical data and finite element (FE) analysis to predict the fracture life of Al-1050 beam with the help of its fundamental mode is presented in this study. Experiments were performed on a non-prismatic beam vibrating with a constant value of the amplitude at the fixed end until the complete fracture of the specimen was achieved. The beam was vibrating on its fundamental mode to achieve fracture in less time. A power law model was used to acquire the possible trends in between the values of natural frequencies and the number of cycles recorded during these experiments. These trends were further compared with a numerically modeled specimen but with artificial cracks. FE modal analysis was used for this comparison. An error of less than $1 \%$ was observed in the estimated number of total cycles obtained through power law model before fracture as compare to those obtained from the numerical approach. Using this approach, fracture life of different length specimens was also predicted.
\end{abstract}

Keywords- Fracture, modal analysis, artificial cracks, finite element analysis, power law. 


\section{Introduction}

Subsurface damage causes the decay in useful life of a mechanical structure. Any variation in this damage alter the modal parameters of the structure during its service lifetime ${ }^{(1)}$. Therefore, it is imperative that one can relate the modal parameters with the damage state and predict the remaining life of structure. Dynamic testing has been widely used to obtain modal parameters (stiffness, natural frequencies, mode shapes and modal damping values) and can be used to monitor the damage variations in the structure. The main emphasis of this research is to determine the potential of the modal parameters (especially the fundamental mode or first natural frequency) of a structure for calculating its useful remaining life i.e. Fracture life.

Mechanical structures theoretically modify their natural frequencies due to any variation in subsurface damage. Therefore, it has been widely used as a diagnostic parameter to monitor the structural integrity. For example, when measured natural frequencies are substantially lower than expected, then they refer to a loss in stiffness, while frequencies higher than expected indicate stiffening of a structure ${ }^{(2)}$. The reduction in natural frequency also depends on the position of the defect relative to the mode shape for a particular mode of vibration ${ }^{(3-8)}$. The selection of the appropriate modes of the natural frequencies is also found to be crucial for damage diagnostic. Results from the experimental ${ }^{(8-9)}$ and the numerical ${ }^{(10)}$ studies have suggested that the vibrations close to fundamental modes would probably be the best suited for damage detection. Begg et al.

(11) have suggested that the higher modes should be used in damage detection to improve the identification of a defect. But due to difficulty in obtaining the higher modes in physical applications, the first mode of vibration can be used effectively.

In recent years, the crack detection and its effects on the dynamic structural characteristics gain substantial attention among researchers. Several analytical, experimental and computational 
studies were performed on the beams. If a crack is present at a particular section then the local bending stiffness of the beam is reduced at that cross-section. Several authors approximate the problem consisting of two beams connected by a torsional spring (which models the section) with a stiffness dependent on the depth of the $\operatorname{crack}^{(6,12)}$. The reduced local bending stiffness results in lowering the values of the natural frequency in bending. Recently, extensive numerical studies were performed to study the characteristic of the vibrating cracked beams from the measurements of changes in resonant frequencies. It covers numerical studies on: the changes of structural stiffness with respect to the position of defects ${ }^{(12)}$, mode shapes of the cracked rotating tapered beam , multiple-crack damage detection and their possible orientation ${ }^{(13-14)}$ and modal analysis of multi-cracked beams with a circular cross section ${ }^{(15)}$. Despite the fact that enormous research has been conducted in the area of damage detection by using changes in modal responses ${ }^{(16-18)}$, changes in the natural frequencies $(16,19,20)$ and changes in mode shapes ${ }^{(21-23)}$, but still the prediction of the operating cycles before catastrophic failure has not yet studied.

A technique based on empirical data and finite element (FE) analysis to predict the fracture life of Al-1050 beam with the help of its fundamental mode is presented in this study. Experiments were performed on a non-prismatic beam vibrating with a constant value of amplitude at the fixed end until the complete fracture of the specimen was achieved. The beam was vibrating on its fundamental mode to achieve fracture in less time. A power law model was used to acquire the possible trends in between the values of modal frequencies and the number of cycles recorded during these experiments. These trends were further compared with a numerically modeled specimen but with artificial cracks. FE modal analysis was used for this comparison. Using this approach, fracture life of different length specimens was predicted which determine its effectiveness in structural health monitoring. 


\section{Methodology}

\section{Materials and geometry}

Experiments were carried out on an Aluminium-1050 cantilever beam at elevated temperature to predict the remaining life of structure based on its natural frequency evolution ${ }^{(24)}$. In this work, the previous setup for dynamic testing of the specimens was utilized. A schematic of the geometry of a typical test specimen is shown in Figure 1. Experiments were performed on Al-1050 cantilever beams with three different lengths i.e. $110 \mathrm{~mm}, 130 \mathrm{~mm}$ and $150 \mathrm{~mm}$. These values are representing the length of the $10 \mathrm{~mm}$ wide cross-section portion of the specimen. For each length, a set of three specimens was tested. The thickness (t) and width (w) of these specimens were selected as $0.5 \mathrm{~mm}$ and $10 \mathrm{~mm}$ respectively. The possible crack location was controlled by this geometry as a high stress concentration was achieved around the $2.5 \mathrm{~mm}$ radius portion ${ }^{(24)}$. A wire cut technique was used to manufacture the specimens with defect-free edges. However, minor defects may appear on the edges which could possibly initiate crack locally in the area other than the radius given in the stress concentration region. Young's modulus, Poisson ratio and density of Al-1050 were considered as $70 \mathrm{GPa}, 0.35$ and $2700 \mathrm{~kg} / \mathrm{m} 3$, respectively.

\section{Experimental Setup}

A modal exciter, a frequency controller and a vibration analyzer were involved in the experimental setup as shown in Figure 2. One end of the specimen was mounted on the Cussons modal exciter (model P1906) which was the primary source for vibrating the specimen at its natural frequency. The other end of the beam was set free. This configuration is normally referred to as the fixed-free vibrating condition. The natural frequency of each specimen before the start of experiment was analytically calculated using the following Timoshenko beam equation (25) for lateral vibration with fixed-free end conditions. 


$$
f_{n}=\frac{\left(\beta_{1} l\right)^{2}}{2 \pi} \sqrt{\frac{E I}{\rho A l^{4}}}=\frac{(1.875104)^{2}}{2 \pi} \sqrt{\frac{E I}{\rho A l^{4}}}=0.5596 \sqrt{\frac{E I}{\rho A l^{4}}}(\mathrm{~Hz})
$$

where ' $\mathrm{E}^{\prime}$ is the modulus of elasticity, ' $\mathrm{I}$ ' is the second moment of inertia, ' $\rho$ ' is the density of material, ' $\mathrm{A}$ ' is the cross-sectional area of thinner section, ' $\mathrm{l}$ ' is the length of specimen and ' $\beta_{1} \mathrm{l}^{\prime}$ is a factor for end condition.

The vibration analyzer was attached to the foundation of the modal exciter. It was used to measure the dynamic response available at the foundation of the modal exciter in a frequency spectrum. As the exciter and the specimen were firmly attached so any measured response can provide a cumulative amplitude of the dynamic response of the whole system which was largely dominated by the specimen displacement at the free end due to the resonance phenomenon. This amplitude was continuously monitored on the analyzer screen with a data sampling frequency of 1 $\mathrm{kHz}$. A change in the structure displacement at the free end was observed by measuring the change in the mentioned amplitude. It is because the exciter had a constant value of the amplitude in all times during the test at the fixed end. A sound meter by Standard Instruments (model: ST-8851) was also placed near the vibrating specimen with a sampling rate of two readings per second. The reason of using the sound meter was to record the time when the possible decrease in the resonance amplitude was observed on the frequency spectrum at the analyzer screen. Subsequently, this time was used to determine the number of cycles between the two successive drops of the natural frequency.

\section{Experimental Procedure}

At the start of each experiment, newly manufactured specimens without any external damage were used. The specimen was then subjected to a dynamic load through a modal exciter that excites the specimen with a fixed value of the amplitude on its first natural frequency. Eq. (1) was used for 
the determination of the fundamental frequency of the fresh specimen in the start. Due to resonance, a very high amplitude was observed on the free end of the specimen and assumed as the maximum available amplitude on the structure. After certain number of cycles, a decrease in the amplitude was observed on the frequency spectrum available at the vibration analyzer. The reason for this decrease could be a crack initiation in the subsurface of the specimen. At this instant, the exciter was stopped and the specimen was tapped with a very light wooden stick which made it vibrate on its all possible modes. A decrease in the first natural frequency value was also recorded on the mentioned spectrum. This observation was then used to a set a new load frequency on the modal exciter. The time between the two consecutive natural frequencies was recorded in number of cycles. On this new frequency, the specimen was again excited on its maximum amplitude at the free end until a decrease in this amplitude was observed. The same procedure was repeated to achieve the fracture on the specimen.

\section{Results and Discussion}

The experimental data with the reducing fundamental frequency during vibration was obtained with the number of cycles. A power law model was developed on the basis of this experimental data which can estimate the fracture life of the specimen of any given length but only requires the observed natural frequency drop at any given instant of time.

\section{a. Experimental work and fracture life power law model}

A typical flow of the experimental work is shown in Figure 3. The Figure 3(a) shows the mounting of the specimen on the modal exciter. The vibrating specimen at resonance condition is shown in Figure 3(b). A typical example of specimen failure is shown in Figure 3(c) showing that the 
specimens were not broken apart but some portion of the specimen remain intact due to the ductile nature of the specimen as shown in Figure 3(d).

For each configuration of the specimen, three separate tests were performed. Table 1(a)-(c) shows the data of the total number of cycles and relevant first natural frequency drop until fracture of the specimen for different lengths. Insignificant variations in the values of natural frequencies and total number of cycles were observed for the same length specimen. The reason for these variations was possibly the dimensional tolerances in manufacturing process of the specimens.

Table 1(a): Natural frequency and total cycles before fracture for three specimens with $\mathrm{L}=110 \mathrm{~mm}$

\begin{tabular}{|c|c|c|c|c|c|}
\hline \multicolumn{2}{|c|}{ Test-1 } & \multicolumn{2}{|c|}{ Test-2 } & \multicolumn{2}{c|}{ Test-3 } \\
\hline $\begin{array}{c}\text { Natural } \\
\text { frequency } \\
(\mathrm{Hz})\end{array}$ & $\begin{array}{c}\text { Total number } \\
\text { of cycles }\end{array}$ & $\begin{array}{c}\text { Natural } \\
\text { frequency } \\
(\mathrm{Hz})\end{array}$ & $\begin{array}{c}\text { Total number } \\
\text { of cycles }\end{array}$ & $\begin{array}{c}\text { Natural } \\
\text { frequency } \\
(\mathrm{Hz})\end{array}$ & $\begin{array}{c}\text { Total number } \\
\text { of cycles }\end{array}$ \\
\hline 31.1 & 34210 & 30.5 & 53375 & 31 & 27822.5 \\
\hline 30.7 & 39583 & 30.1 & 55707.75 & 30.8 & 49182.3 \\
\hline 30.4 & 44903 & 29.5 & 57389.25 & 28 & 49602.3 \\
\hline 30 & 46103 & 29 & 59216.25 & 27.5 & 50441.05 \\
\hline 29.4 & 47720 & 28.4 & 59713.25 & 26.5 & 51143.3 \\
\hline 28.4 & 48288 & 28 & 61183.25 & 25.6 & 51847.3 \\
\hline 28 & 49198 & 19.5 & 61349 & 18.5 & 52134.05 \\
\hline 26.8 & 49680 & 19 & 61472.5 & 17.6 & 52310.05 \\
\hline 21 & 49896 & 18 & 61553.5 & 16.9 & 52380.05 \\
\hline 19 & 49967 & 17 & 61604.5 & & \\
\hline 17.2 & 50147 & 16.5 & 61628.5 & & \\
\hline
\end{tabular}

Table 1(b): Natural frequency and total cycles before fracture for three specimens with $\mathrm{L}=130 \mathrm{~mm}$

\begin{tabular}{|c|c|c|c|c|c|}
\hline \multicolumn{2}{|c|}{ Test-1 } & \multicolumn{2}{|l|}{ Test-2 } & \multicolumn{2}{l|}{ Test-3 } \\
\hline $\begin{array}{c}\text { Natural } \\
\text { frequency } \\
(\mathrm{Hz})\end{array}$ & $\begin{array}{c}\text { Total number } \\
\text { of cycles }\end{array}$ & $\begin{array}{c}\text { Natural } \\
\text { frequency } \\
(\mathrm{Hz})\end{array}$ & $\begin{array}{c}\text { Total number } \\
\text { of cycles }\end{array}$ & $\begin{array}{c}\text { Natural } \\
\text { frequency } \\
(\mathrm{Hz})\end{array}$ & $\begin{array}{c}\text { Total number } \\
\text { of cycles }\end{array}$ \\
\hline 21.4 & 432449.4 & 22 & 630784 & 21.5 & 408430 \\
\hline 20.2 & 817623 & 21.5 & 685318.75 & 21 & 558580 \\
\hline
\end{tabular}




\begin{tabular}{|c|c|c|c|c|c|}
\hline 20 & 840463 & 21 & 773518.75 & 20.8 & 729857.6 \\
\hline 19.8 & 852996.4 & 20 & 784268.75 & 20.5 & 732676.35 \\
\hline 19 & 858031.4 & 19.7 & 786514.55 & 20.3 & 743618.05 \\
\hline 18.3 & 859092.8 & 19 & 787588.05 & 19.8 & 754092.25 \\
\hline 18 & 861387.8 & 18.2 & 788416.15 & 19.4 & 758602.75 \\
\hline 17.5 & 862131.55 & 17 & 788866.65 & 19.1 & 761143.05 \\
\hline 17.2 & 863051.75 & 14 & 789167.65 & 18.7 & 762283.75 \\
\hline 17 & 863578.75 & & & 18.4 & 763737.35 \\
\hline 16.8 & 863948.35 & & & 17.8 & 764315.85 \\
\hline 16.3 & 864421.05 & & & 17.5 & 765339.6 \\
\hline 15.5 & 864909.3 & & & 16.5 & 765636.6 \\
\hline 14 & 865154.3 & & & 16.2 & 765920.1 \\
\hline 13.3 & 865234.1 & & & 15.3 & 766233.75 \\
\hline & & & & 14.8 & 766574.15 \\
\hline & & & & 13.5 & 766776.65 \\
\hline
\end{tabular}

Table 1(c): Natural frequency and total cycles before fracture for three specimens with $\mathrm{L}=150 \mathrm{~mm}$

\begin{tabular}{|c|c|c|c|c|c|}
\hline \multicolumn{2}{|c|}{ Test-1 } & \multicolumn{2}{c|}{ Test-2 } & \multicolumn{2}{c|}{ Test-3 } \\
\hline $\begin{array}{c}\text { Natural } \\
\text { frequency } \\
\text { (Hz) }\end{array}$ & $\begin{array}{c}\text { Total number } \\
\text { of cycles }\end{array}$ & $\begin{array}{c}\text { Natural } \\
\text { frequency } \\
(\mathrm{Hz})\end{array}$ & $\begin{array}{c}\text { Total number } \\
\text { of cycles }\end{array}$ & $\begin{array}{c}\text { Natural } \\
\text { frequency } \\
\text { (Hz) }\end{array}$ & $\begin{array}{c}\text { Total number } \\
\text { of cycles }\end{array}$ \\
\hline 16.9 & 262550 & 16.8 & 210579.6 & 16.2 & 176620.5 \\
\hline 16.5 & 340982.75 & 16.5 & 288311.1 & 16 & 189660.5 \\
\hline 15.8 & 341456.75 & 15.2 & 290864.7 & 15.9 & 207389 \\
\hline 15.6 & 345036.95 & 13.1 & 291008.8 & 15.7 & 211510.25 \\
\hline 15.2 & 346222.55 & 12.8 & 291207.2 & 15.3 & 219275 \\
\hline 15 & 348165.05 & 12.2 & 291310.9 & 15.1 & 222446 \\
\hline 14.5 & 348810.3 & 11.1 & 291416.35 & 14.9 & 224882.15 \\
\hline 14 & 349377.3 & 10 & 291466.35 & 14.8 & 226125.35 \\
\hline 13 & 349916.8 & & & 14.4 & 227277.35 \\
\hline 12 & 350222.8 & & & 14 & 228264.35 \\
\hline 10.4 & 350336.8 & & & 13.7 & 229011 \\
\hline & & & & 13.5 & 229395.75 \\
\hline & & & & 13.3 & 229668.4 \\
\hline & & & & 13 & 229967.4 \\
\hline
\end{tabular}




\begin{tabular}{|c|c|c|c|c|c|}
\hline & & & & 12.8 & 230217 \\
\hline & & & & 12.4 & 230483.6 \\
\hline & & & & 12 & 230807.6 \\
\hline & & & & 10 & 230922.6 \\
\hline
\end{tabular}

The data obtained from the above experimental results was the basis to develop a power law model for the fracture life of the specimens with different length values. The fracture life of the specimens (Y) of any given length as a function of the first mode of the natural frequency (X) at a given instant was estimated. The expression of a power law was used as

$$
Y=m X^{b}+c
$$

The constants $\mathrm{m}, \mathrm{b}$ and $\mathrm{c}$ were calculated from the experimental data at different lengths as shown in Table 2. However, according to Eq. (1), the natural frequency depends on specimen geometry, its material properties and its boundary or end conditions. If one changes the specimen geometry or material, new sets of fatigue tests must be performed to develop a new power law for the prediction of fracture life.

Table 2: Power law constant for different lengths.

\begin{tabular}{|c|c|c|c|}
\hline \multirow[b]{2}{*}{ Length } & \multicolumn{3}{|c|}{ Constants } \\
\hline & $\mathrm{b}$ & $\mathrm{m}$ & $\mathrm{c}$ \\
\hline 150 & 12.23 & $-1.184 \mathrm{e}-10$ & $2.95 \mathrm{e} 5$ \\
\hline 130 & 11.04 & $-4.498 \mathrm{e}-10$ & $8.41 \mathrm{e} 5$ \\
\hline 110 & 9.903 & $-2 e-11$ & $5.578 \mathrm{e} 4$ \\
\hline
\end{tabular}

An implicit expression for $b, \mathrm{~m}$ and $\mathrm{c}$ as a function of specimen length can be used to predict the fracture life for a given length. The equations for constants $b, \mathrm{~m}$ and $\mathrm{c}$ were found as:

$$
b=0.0003877 L^{3.324}+9.086
$$


$m=6.179 e^{-11} L^{2}-1.565 e^{-9} L+9.44 e^{-9}$
$c=-1.069 e^{5} L^{2}+2.722 e^{6} L-1.646 e^{7}$

Three more experiments on different lengths were performed and estimation of total number of cycles by using the power law was analyzed. The testing lengths were: $120 \mathrm{~mm}, 140 \mathrm{~mm}$ and $145 \mathrm{~mm}$. The obtained experimental results and their comparisons with power law is shown in Figure 4 . In all the estimated values, $43 \%$ are predicted with less than $10 \%$ of error, $28 \%$ are predicted with less than $15 \%$ of error and $29 \%$ are predicted with less than $20 \%$ of error. The above experiments on new lengths show the stochastic nature of the obtained data. The calculated error ranges fairly show the capability of the model estimation on non-calibrated lengths. However, it indicates that the devised power law needs more calibration on new lengths of the selected range with a low step of length.

\section{b. Numerical Modal Analysis}

A finite element (FE) modal analysis was also performed on the numerically modelled test specimens with predefined artificial cracks of different depths. A three dimensional analysis along with convergence study was used to obtain the proper mesh size. A rectangular artificial crack was made and located at $13 \mathrm{~mm}$ from fixed end. The width of the crack was taken as $1 \mathrm{~mm}$ and remained constant in all the simulations. In contrast, the depth of the crack was used in a range of $0.025 \mathrm{~mm}$ to $0.249 \mathrm{~mm}$.

In FE modeling, one of the possible ways a crack could be propagated was selected until a natural frequency drop was achieved which was similar to the experimental result. The geometry of the crack was drawn as rectangular which further propagated symmetrically from the top and the bottom surfaces of the specimen as shown in Figure 5 (a). Theoretically, this type of crack propagation behavior may not exactly represent the actual crack phenomena in the specimen. There 
are two fundamental facts which actually makes this assumption of symmetrical crack of both sides fairly acceptable. First, the specimen was under constant reverse bending load which could equally produce the same stresses on both sides of the specimen. Secondly, uniform damage wrinkles on both side of the specimen were also observed during the tests. Damage from the top side is shown in Figure 5 (b).

In this research, the reason of a decrease in natural frequency was assumed as an increase of the crack depth in the specimens. Natural frequencies of the cracked specimens were obtained by the FE analysis and hence a data of the frequency drops at different values of crack depths was determined. Therefore during analysis, those depths were selected which could provide a frequency drop comparable to the ones obtained from the experimental data. In this way, a correlation between life predictions of the cracked beam vibrating at its corresponding natural frequency state was developed. The maximum possible depth of the artificial crack with its value of frequency drop was further validated with the total number of cycles before fracture obtained from the power law model. After an acceptable error between the experimental and numerical results, the power law and the finite element model were used to estimate the fracture life of specimens with arbitrary values of lengths.

Figure 6(a) shows the comparison of natural frequency and crack depth as obtained from the experimental data and the numerical study. The numerical results were in close agreement with the specimen experimental fracture natural frequency. An error of maximum 1\% error was observed. The error was calculated as the ratio of the difference between experimental and numerical fracture frequency to the experimental fracture frequency). The normalized frequency verses the normalized crack depth ratio for different specimen length is shown in Figure 6(b). Similar trend 
in drop of normalized fundamental mode of natural frequency was observed with the increasing crack depth.

\section{c. Fracture life estimation on arbitrary values of length of specimen}

Four arbitrary lengths of the specimen were selected: $170 \mathrm{~mm}, 180 \mathrm{~mm}, 200 \mathrm{~mm}$ and $250 \mathrm{~mm}$. In the absence of the empirical data, their possible fracture life was estimated by using the established power law model and finite element model. Figure 7(a) shows the first mode of natural frequency for a given crack depth in each specimen by using the finite element model for each selected length values. Using this data, the frequency at a given corresponding crack depth was used in Power law (Eq. 3-5) for a specific length of the specimen to predict the number of cycles. This prediction of number of cycles at different crack depth is shown in Figure 7(b). Thus, using this graph at a given number of cycles, the possible crack size was predicted. It was also observed that with the increase of specimen length the natural frequency decreases, but the number of cycles for fracture increases. The predicted remaining life cycles were reaching to a very low value just before the maximum possible depth of the crack. An error of 5\% was observed between the finite element analysis and the power law predictions.

\section{CONCLUSION}

A methodology is proposed to predict the fracture life of Al 1050 beam with the help of its fundamental mode. The fracture life of structure (i.e. beam in the presented case) can be predicted on the basis of the possible drop of its first mode of natural frequency. Experimental data of selected lengths of specimens with a finite element modal analysis was used to predict fracture life of the specimen of any given length. It is observed that the predicted remaining life cycles were reaching to a very low value just before the maximum possible depth of the artificial crack and hence it 
demonstrates the effectiveness of the adopted methodology. The main assumption of the proposed method is the shape of the artificial crack and path of crack propagation. However, an extension of this work will focus on different shapes of the cracks and their behavior in fracture prediction. Further, this procedure can also be used to analyze the crack propagation path and its rates without dismantling the structural element from its routine operations.

\section{REFERENCES}

[1] R. K. Behera, A. Pandey, and D. R. Parhi, "Numerical and Experimental Verification of a Method for Prognosis of Inclined Edge Crack in Cantilever Beam based on Synthesis of Mode Shapes," Procedia Technol., vol. 14, pp. 67-74, 2014.

[2] B. J. Morgan and R. G. Oesterle, "On-site modal analysis-a new powerful inspection technique," in Proceedings of the 2nd International Bridge Conference, pp. 108-114, 1985.

[3] R. D. Adams, P. Cawley, C. J. Pye, and B. J. Stone, "A vibration technique for non-destructively assessing the integrity of structures," J. Mech. Eng. Sci., vol. 20, no. 2, pp. 93-100, 1978.

[4] T. G. Chondros and A. D. Dimarogonas, "Identification of cracks in welded joints of complex structures," J. Sound Vib., vol. 69, no. 4, pp. 531-538, 1980.

[5] P. Gudmundson, "Eigenfrequency changes of structures due to cracks, notches or other geometrical changes," J. Mech. Phys. Solids, vol. 30, no. 5, pp. 339-353, 1982.

[6] A. Gomes, "On the use of modal analysis for crack identification," in International Modal Analysis Conference, 8 th, Kissimmee, FL, pp. 1108-1115, 1990.

[7] W. T. Springer, K. L. Lawrence, and T. J. Lawley, "Damage assessment based on the structural frequency-response function," Exp. Mech., vol. 28, no. 1, pp. 34-37, 1988.

[8] M. Moradalizadeh, "Evaluation of crack defects in framed structures using resonant frequency techniques," University of Newcastle upon Tyne, 1990.

[9] J. Slastan and S. Pietrzko, "Changes of RC-beam modal parameters due to cracks," in PROCEEDINGS OF THE INTERNATIONAL MODAL ANALYSIS CONFERENCE, pp. 70-70, 1993.

[10] J. M. Brownjohn, "Assessment of structural integrity by dynamic measurements," University of Bristol, 1988.

[11] R. D. Begg, A. C. Mackenzie, C. J. Dodds, and O. D. Loland, "Structural Integrity Monitoring Using Digital Processing of Vibration Siqnals," in Offshore Technology Conference, 1976.

[12] S. S. Law, L. Xun, and H. S. Ward, "A vibration technique for structural stiffness identification," Proc. Int. Con- F Renee Vib. Probl. Eng, 1990.

[13] A. Maghsoodi, A. Ghadami, and H. R. Mirdamadi, "Multiple-crack damage detection in multi-step beams by a novel local flexibility-based damage index," J. Sound Vib., vol. 332, no. 2, pp. 294-305, 2013.

[14] M. Akbarzadeh Khorshidi and D. Soltani, "Diagnosis of Type, Location and Size of Cracks by Using Generalized Differential Quadrature and Rayleigh Quotient Methods," J. Theor. Appl. Mech., vol. 43, no. 1, pp. 61-70, 2013.

[15] M. Kisa and M. A. Gurel, "Free vibration analysis of uniform and stepped cracked beams with circular cross sections," Int. J. Eng. Sci., vol. 45, no. 2, pp. 364-380, 2007. 
[16] P. Cawley and R. D. Adams, "The location of defects in structures from measurements of natural frequencies," J. Strain Anal. Eng. Des., vol. 14, no. 2, pp. 49-57, Apr, 1979.

[17] A. K. Pandey, M. Biswas, and M. M. Samman, "Damage detection from changes in curvature mode shapes," J. Sound Vib., vol. 145, no. 2, pp. 321-332, 1991.

[18] N. Stubbs and J.-T. Kim, "Damage localization in structures without baseline modal parameters," Aiaa J., vol. 34, no. 8, pp. 1644-1649, 1996.

[19] W. M. Ostachowicz and M. Krawczuk, "Vibration analysis of a cracked beam," Comput. Struct., vol. 36 , no. 2, pp. 245-250, 1990.

[20] J. N. Sundermeyer and R. L. Weaver, "On crack identification and characterization in a beam by non-linear vibration analysis," J. Sound Vib., vol. 183, no. 5, pp. 857-871, 1995.

[21] N. Stubbs and R. Osegueda, "Global non-destructive damage evaluation in solids," Int. J. Anal. Exp. Modal Anal., vol. 5, pp. 67-79, 1990.

[22] A. K. Pandey and M. Biswas, "Damage detection in structures using changes in flexibility," J. Sound Vib., vol. 169, no. 1, pp. 3-17, 1994.

[23] J.-T. KIM, S.-H. JUNG, Y.-K. LEE, and J.-W. YUN, "Damage identification in bridges using vibrationbased system identification scheme," in SPIE proceedings series, pp. 1327-1333, 2000.

[24] M. A. Khan, S. Z. Khan, W. Sohail, H. Khan, M. Sohaib, and S. Nisar, "Mechanical fatigue in aluminium at elevated temperature and remaining life prediction based on natural frequency evolution," Fatigue Fract. Eng. Mater. Struct, 2015.

[25] Singiresu S. Rao, Mechanical Vibrations $4^{\text {th }}$ ed., Prentice Hall, US, 2006. 
Figures

Figure -1 : Schematic of the geometry of a typical test specimen used in the experiments with thickness $(\mathrm{t})=0.5 \mathrm{~mm}$ (all dimensions are in $\mathrm{mm}$ )

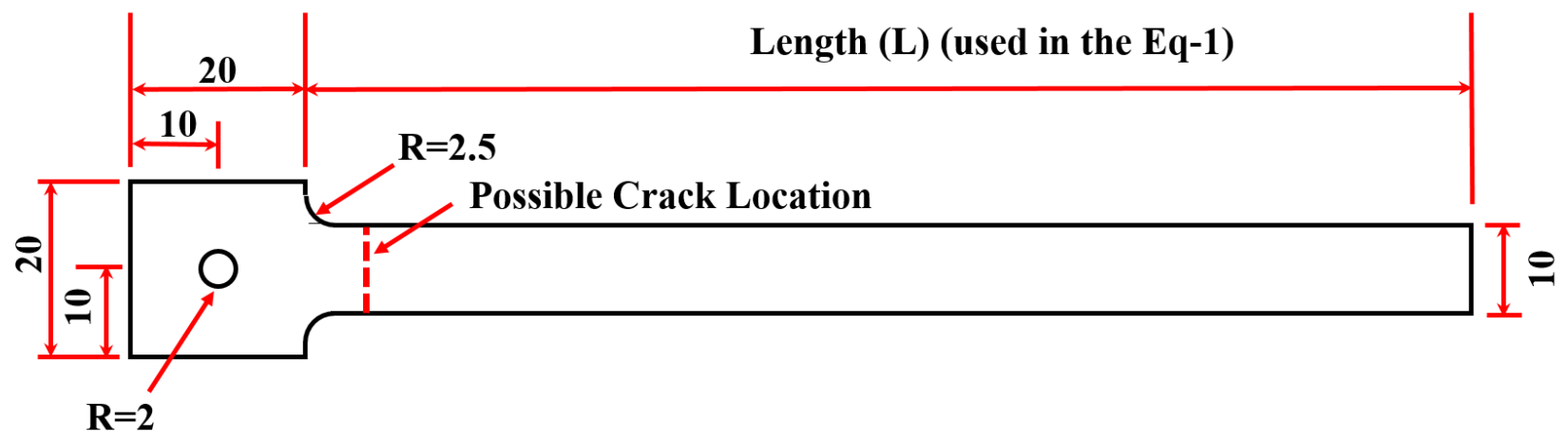

Figure 2. Experimental set-up for dynamic testing of specimens using the data acquisition system. Inset: a zoomed-in view of the specimen and the modal exciter

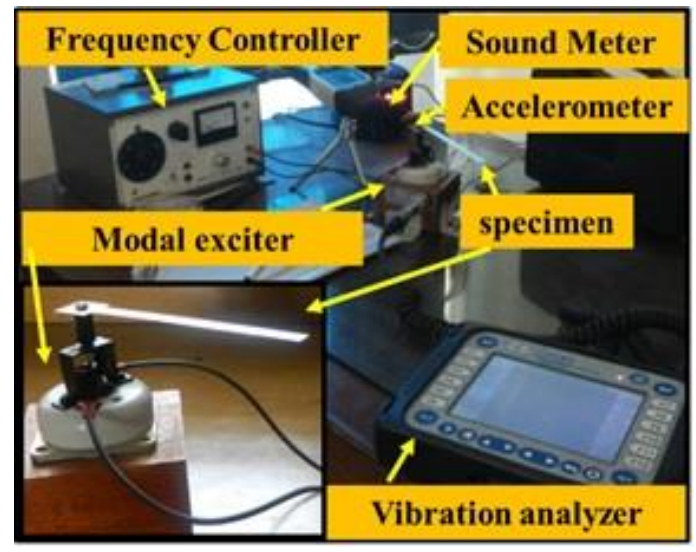

Figure 3. Experimental process: (a) stationary specimen before the start of the experiment; (b) vibrating specimen showing the amplitude at resonant frequency; (c) fractured specimen; and (d) unbroken intact area of the specimen after fracture
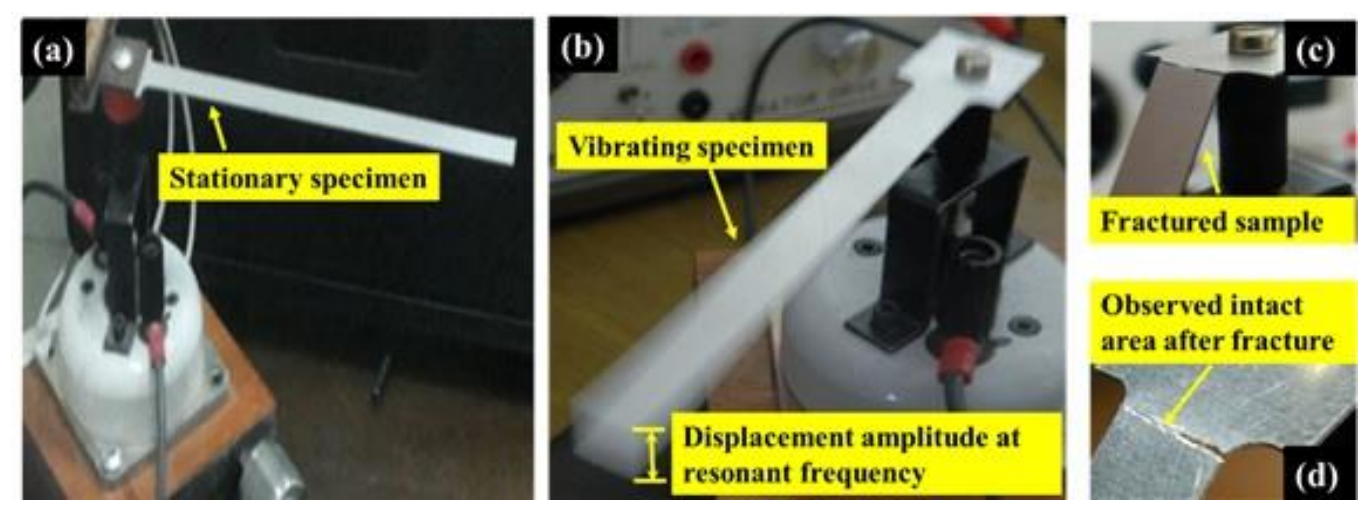
Figure 4. Comparison of fracture life cycles on non-calibrated lengths: experiments versus power law

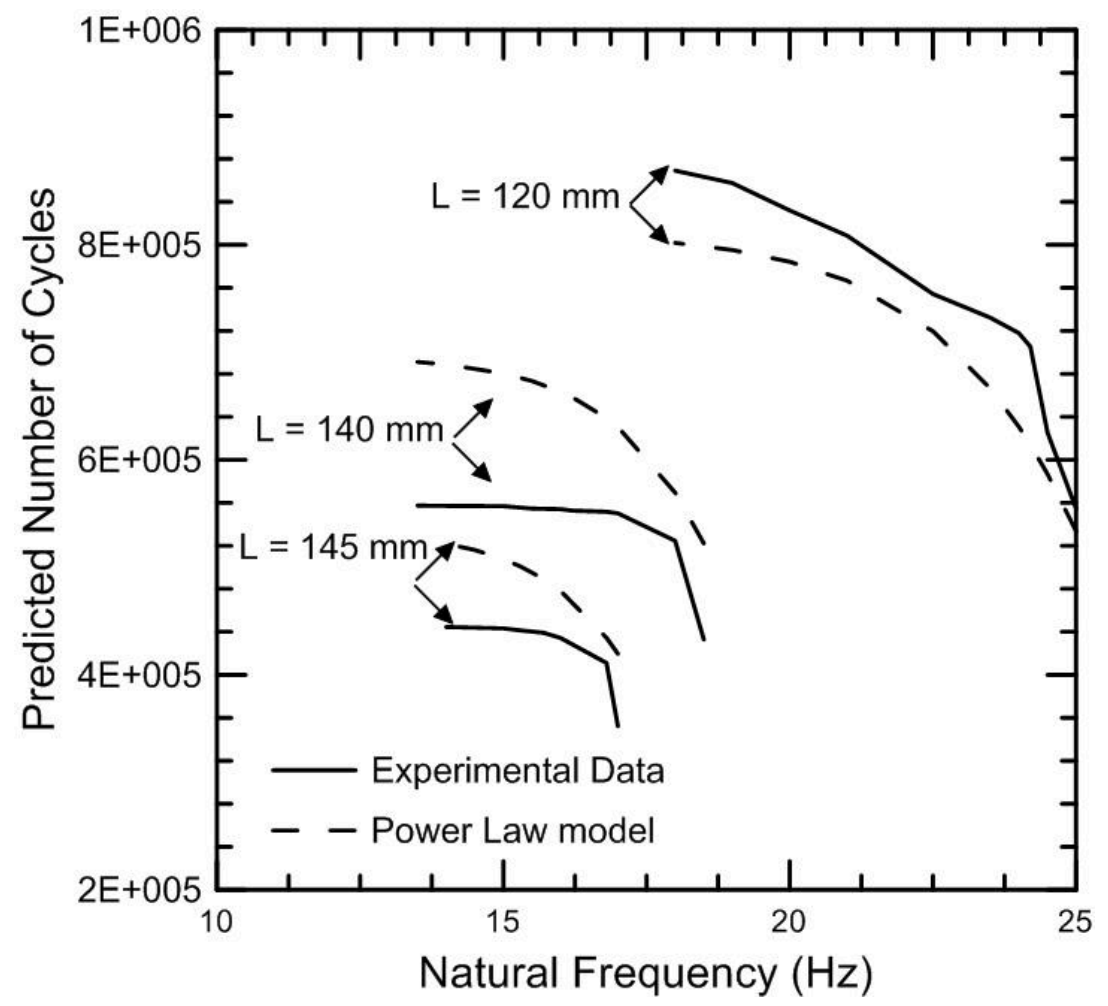

Figure 5. (a) FE model with boundary condition for modal analysis; and (b) enlarged view of the specimen showing crack geometry near fillet (a crack with constant width and length but varying depth is considered in simulations)

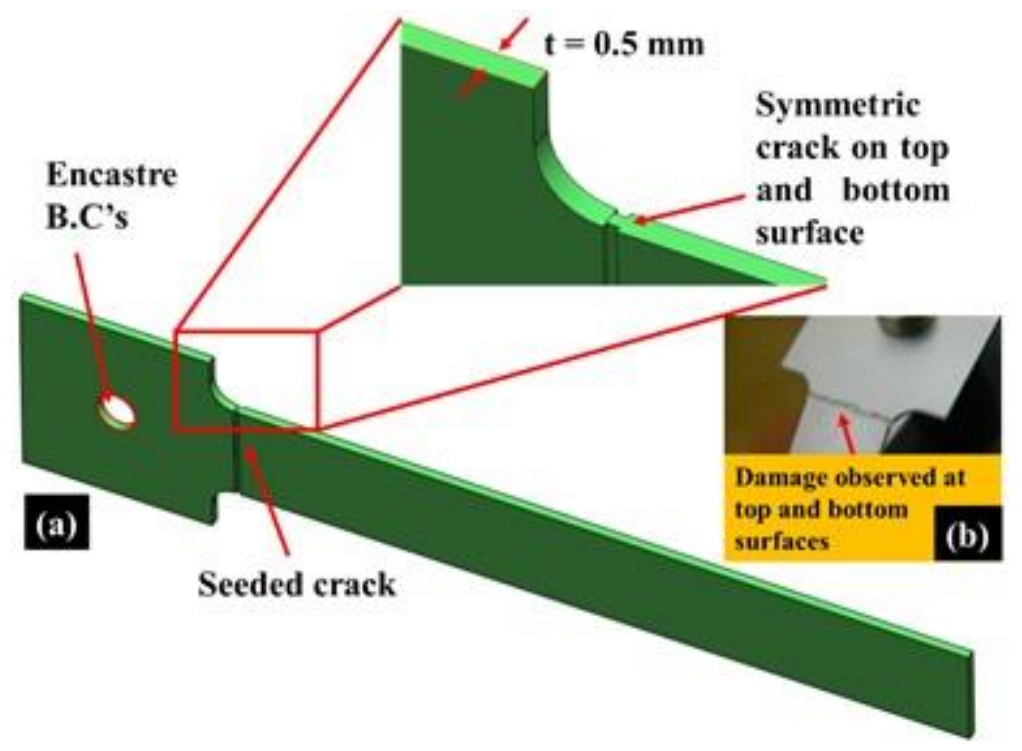


Figure 6. (a) Comparison of numerical and experimental data of the natural frequency evolution and the crack depth obtained from different specimen lengths; and (b) corresponding normalised frequency versus normalised crack depth
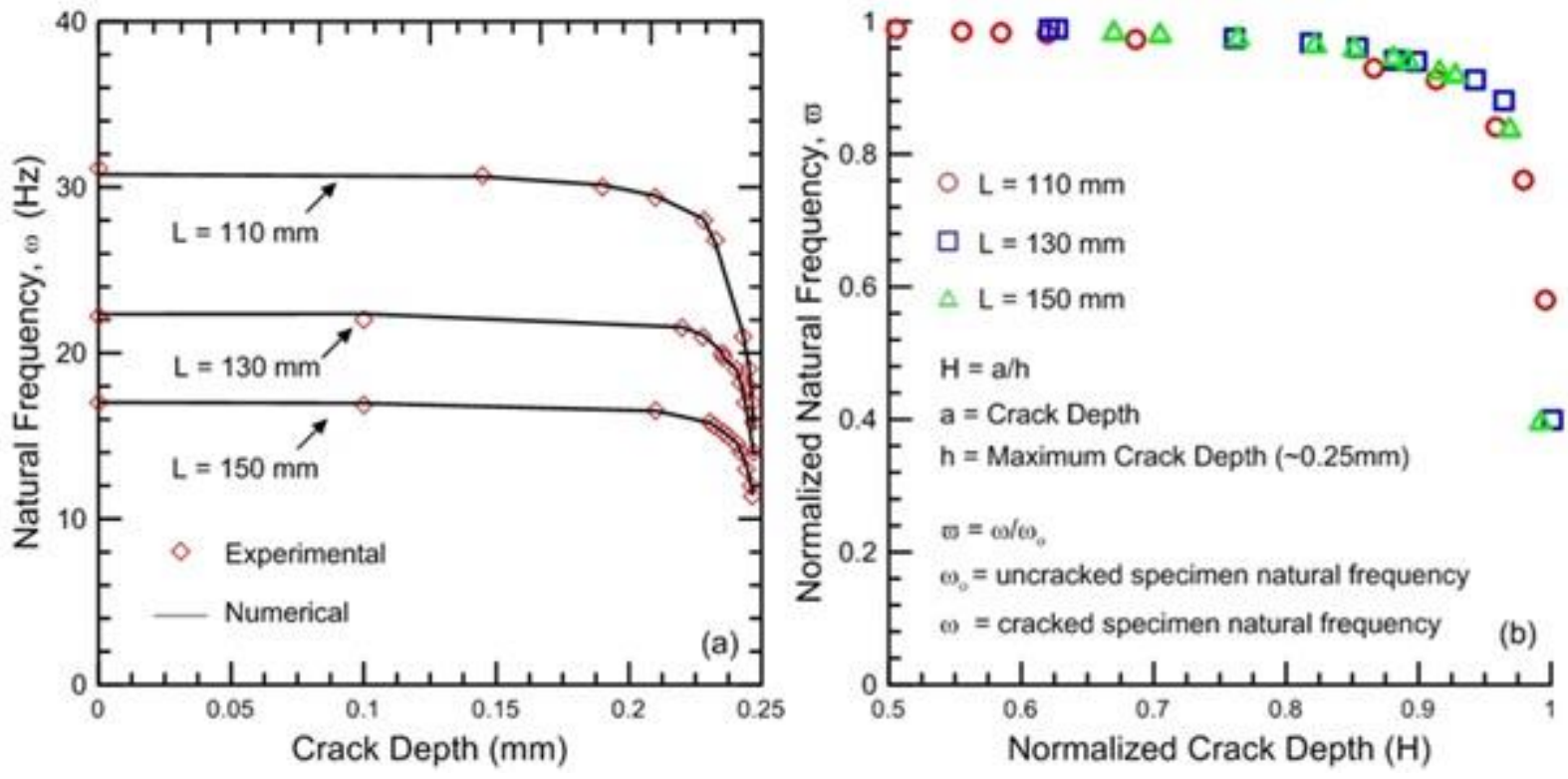

Figure 7. (a) Prediction of natural frequency drop with respect to the crack growth using FE modal analysis; and (b) predicted number of cycles for failure with respect to the crack growth for different specimen lengths using the power law model
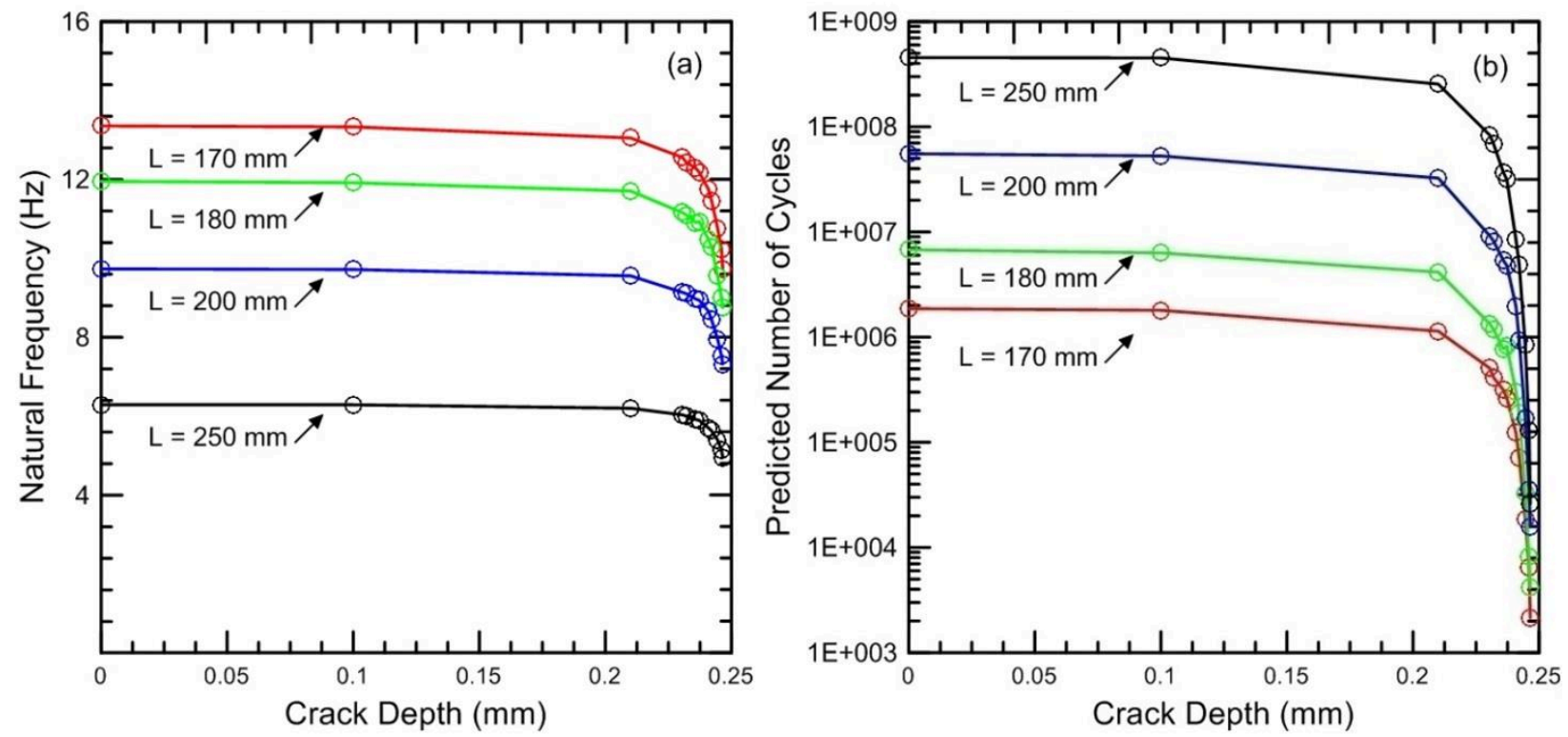
2018-07-01

Fracture life estimation of $\mathrm{Al}-1050$ thin beams using empirical data and a numerical approach

\author{
Khan, Muhammad Ali
}

British Institute of Non-destructive Testing

Khan M, Khan K, Khan S, et al., (2018) Fracture life estimation of Al-1050 thin beams using empirical data and a numerical approach. Insight: Non-Destructive Testing \& Condition Monitoring, Volume 60, Issue 7, July 2018, pp. 363-368

https://doi.org/10.1784/insi.2018.60.7.363

Downloaded from Cranfield Library Services E-Repository 